\title{
Modeling of Viscosity and Thermal Expansion of Bioactive Glasses
}

\author{
Saad B. H. Farid \\ Department of Materials Engineering, University of Technology, Baghdad 10066, Iraq \\ Correspondence should be addressed to Saad B. H. Farid, dr.saadbhf@gmail.com
}

Received 9 October 2012; Accepted 8 November 2012

Academic Editors: P. Valerio and C.-F. Yang

Copyright () 2012 Saad B. H. Farid. This is an open access article distributed under the Creative Commons Attribution License, which permits unrestricted use, distribution, and reproduction in any medium, provided the original work is properly cited.

The behaviors of viscosity and thermal expansion for different compositions of bioactive glasses have been studied. The effect of phosphorous pentoxide as a second glass former in addition to silica was investigated. Consequently, the nonlinear behaviors of viscosity and thermal expansion with respect to the oxide composition have been modeled. The modeling uses published data on bioactive glass compositions with viscosity and thermal expansion. $L^{2}$-regression optimization technique has been utilized for analysis. Linear and nonlinear relations are shown to establish the viscosity and thermal expansion coefficients associated with oxide components of the glasses under study. The modeling allows the calculation of viscosity for a given temperature and, accordingly, the fusion temperature of these glasses along with the coefficient of thermal expansion. The established model relations also suggest first- and second-order phosphorus-alkali and alkaline earth oxides interaction which is reflected on the model coefficient that calculates viscosity and thermal expansion.

\section{Introduction}

In a review of the importance of comprehensive information on glass and melt properties both for the glass science and technology by Mazurin [1], it is shown that the number of publications per year concerning glass property measurements have decreased quite considerably after 1975. Moreover, the frequency of some quite important but labor-consuming property measurements decreases steadily. Besides that, these measurements are quite time and money consuming; thus, the specialist on glass science and technology needs to predict the glass properties via calculation of it. This task must be based on modeling methods which use experimental property data and calculate glass properties including newly designed glasses.

The changes in the composition area of glass often lead to the change of the reliable modeling, that is, different models may be needed. Finding the most reliable model is possible only by comparing the results of property calculations with experimental data for glasses belonging to a system of interest. Next, the model with a minimal root-mean-square error is selected. After that, the model is used for future calculations of glass properties. At present, this is the best way to obtain a property value that is as near to the true one as possible. This explains why modeling of glass properties is an enduring active field in glass science and technology [2].

Viscosity at given temperature and the coefficient of thermal expansion CTE for bioactive glasses are the glass properties which are focused on in this study. Bioactive glasses have the property of forming an apatite layer; thus, when the implants is coated with bioactive glass, it can chemically bond to bone [3]. However, if there is a large difference in coefficient of thermal expansions between the coating and the implant, the bioactive glass will crack resulting in incomplete coating. A second problem is that the fusion temperature is needed to be well estimated for efficient cast of the glass coating to the implant. The fusion temperature should be low enough to avoid phase transformation and degradation of the mechanical properties of the implant. Therefore, scientific efforts must be carried out to achieve glass compositions that are suitable in view of fusion temperature and coefficient of thermal expansion [4]. The glass designer intends to assemble bioactive glass with fusion temperature below $900^{\circ} \mathrm{C}$ to avoid possible phase 
TABLE 1: The composition and thermal properties for reference glasses.

\begin{tabular}{lccccccccc}
\hline No. & $\mathrm{wt} \% \mathrm{SiO}_{2}$ & $\mathrm{wt} \% \mathrm{P}_{2} \mathrm{O}_{5}$ & $\mathrm{wt} \% \mathrm{Na}_{2} \mathrm{O}$ & $\mathrm{wt} \% \mathrm{~K}_{2} \mathrm{O}$ & $\mathrm{wt} \% \mathrm{CaO}$ & $\mathrm{wt} \% \mathrm{MgO}$ & $\mathrm{Ts}(\mathrm{K})$ & $\mathrm{Tg}(\mathrm{K})$ & $\mathrm{CTE}\left(10^{-6}{ }^{\circ} \mathrm{K}\right)$ \\
\hline 1 & 45.0 & 6.0 & 24.5 & 0.0 & 24.5 & 0.0 & 784 & 830 & 15.1 \\
2 & 44.2 & 6.0 & 23.6 & 6.5 & 12.6 & 7.1 & 722 & 776 & 15.6 \\
3 & 44.2 & 6.0 & 17.0 & 4.6 & 18.0 & 10.2 & 789 & 833 \\
4 & 44.2 & 6.0 & 10.3 & 2.8 & 23.4 & 13.3 & 800 & 872 & 13.0 \\
5 & 49.8 & 6.0 & 15.5 & 4.2 & 15.6 & 8.9 & 795 & 833 & 11.3 \\
6 & 52.7 & 6.0 & 17.0 & 4.6 & 12.6 & 7.1 & 803 & 838 & 12.2 \\
7 & 52.7 & 6.0 & 10.3 & 2.8 & 18.0 & 10.2 & 804 & 881 & 11.5 \\
8 & 54.5 & 6.0 & 12.0 & 4.0 & 15.0 & 8.5 & 821 & 875 \\
9 & 56.5 & 6.0 & 11.0 & 3.0 & 15.0 & 8.5 & 830 & 882 & 11.0 \\
10 & 61.1 & 6.0 & 10.3 & 2.8 & 12.6 & 7.2 & 837 & 897 & 10.8 \\
11 & 67.7 & 6.0 & 8.3 & 2.2 & 10.1 & 5.7 & 838 & 917 & 8.2 \\
\hline
\end{tabular}

TABLE 2: Reference experimental $\mathrm{E} \mu(\mathrm{kJ}), \ln A$, and CTE $\left(10^{-6}{ }^{\circ} \mathrm{K}\right)$ versus their calculated values.

\begin{tabular}{lcccccc}
\hline No. & $E \mu$ & $E \mu c$ & $\ln A$ & $\ln A c$ & $\mathrm{CTE}$ & $\mathrm{CTE} c$ \\
\hline 1 & 927.5 & 927.2 & 125.9 & 122.8 & 15.1 & 15.1 \\
2 & 681.5 & 679.8 & 97.1 & 85.9 & 15.6 & 15.6 \\
3 & 979.0 & 986.6 & 132.9 & 131.7 & 13.0 & 13.2 \\
4 & 637.6 & 636.6 & 79.5 & 79.5 & 11.3 & 11.3 \\
5 & 1141.1 & 1106.5 & 156.3 & 149.5 & 12.2 & 12.4 \\
6 & 1258.2 & 1279.3 & 172.1 & 175.3 & 12.9 & 12.5 \\
7 & 605.7 & 608.7 & 74.3 & 75.3 & 11.5 & 11.0 \\
8 & 872.9 & 870.2 & 111.6 & 114.3 & 11.0 & 11.0 \\
9 & 821.7 & 848.8 & 101.8 & 111.1 & 10.8 & 11.0 \\
10 & 923.4 & 905.6 & 117.5 & 119.6 & 10.2 & 10.4 \\
11 & 640.4 & 639.8 & 75.6 & 79.9 & 8.8 & 8.9 \\
\hline
\end{tabular}

transformation of for example, Ti-alloys; also, the value CTE should be around $9.6 \times 10^{-6}{ }^{\circ} \mathrm{K}$ which should match that of Ti-alloys [5]. In addition, the trend in bioactive glass compositions is to set $\mathrm{P}_{2} \mathrm{O}_{5}$ content to $6 \%$ with high $\mathrm{CaO}$ content to ensure the formation of apatite layer after implantation that is responsible for the biocompatibility of the glass.

In general, viscosity and thermal expansion for bioactive glass shows nonlinear behavior with glass composition. Therefore, any proposed model should express effective composition-related terms that describe these properties for bioactive glass. Consequently, the model calculation can be used in design technology in such glass category [6].

The topic of predicting the viscosity and thermal expansion of bioactive glass is still vigorous for different sets of bioactive glass compositions [6, 7], and the modeling study based on formerly published data is still on focus in the applied ceramics community [8-10]. This work presents modeling methodology, results, and discussion of the modeled bioactive class along with the comparison on the effect of $\mathrm{CaO}$ and $\mathrm{MgO}$ content on the properties of the bioactive glass.

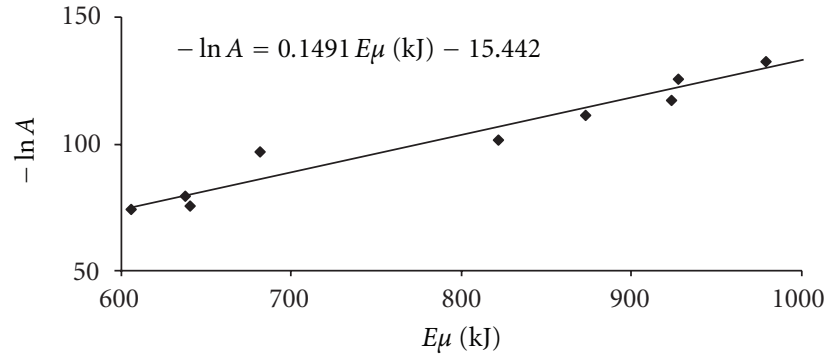

Figure 1: $\ln A$ versus $E \mu$. The equation of least-squares line representing the data is also shown.

\section{Composition-Viscosity and Thermal Expansion Model}

The variation of viscosity $\mu$ with the absolute temperature $T$ is expressed as the following [11]:

$$
\mu=A T \exp \left(\frac{E \mu[J]}{R T}\right) .
$$

The parameter $A$ is constants, $R$ is the gas constant, and $E \mu$ is the activation energy of the viscous process.

The natural logarithm of (1) readsas the following:

$$
\operatorname{Ln}\left(\frac{\mu}{T}\right)=\ln A+\frac{E \mu[J]}{R T} .
$$

The above equation shows that $E \mu$ and $-\ln A$ are linked linearly. Accordingly, values of $\ln A$ can be calculated for a given set of viscosity $\mu$ at temperature $T$ and $E \mu$ for a range of glass compositions.

$E \mu$ is as function of glass composition as well as the coefficient of thermal expansion CTE [12]:

$$
\begin{gathered}
E \mu=\sum_{i=1}^{i=n} C_{i} \cdot N_{i} \\
\mathrm{CTE}=\sum_{i=1}^{i=n} C_{\mathrm{TE} i} \cdot N_{i},
\end{gathered}
$$


TABle 3: Coefficients $C_{i}$ and $C_{\mathrm{TE} i}$ associated with the glass composition.

\begin{tabular}{lcccccccc}
\hline Term & $\mathrm{wt} \% \mathrm{SiO}_{2}$ & $\mathrm{wt} \% \mathrm{P}_{2} \mathrm{O}_{5}$ & $\mathrm{wt} \% \mathrm{~K}_{2} \mathrm{O}$ & $\mathrm{Wt} \% \mathrm{MgO}$ & $R_{11}$ & $R_{12}$ & $R_{21}$ \\
\hline E $\mu$ coefficient & $C_{1}$ & $C_{2}$ & $C_{3}$ & $C_{4}$ & $C_{5}$ & $C_{6}$ & $C_{7}$ & $C_{8}$ \\
Value & 39.82 & -1355 & -135.9 & 82.27 & 83645 & -54473 & -66823 & 44794 \\
\hline CTE coefficient & $C_{\mathrm{TE} 1}$ & $C_{\mathrm{TE} 2}$ & $C_{\mathrm{TE} 3}$ & $C_{\mathrm{TE} 4}$ & $C_{\mathrm{TE} 5}$ & $C_{\mathrm{TE} 6}$ & $C_{\mathrm{TE7}}$ & $C_{\mathrm{TE} 8}$ \\
Value & -0.62 & -7.62 & -0.84 & -0.37 & -64.65 & 36.09 & 395.01 & -309.81 \\
\hline
\end{tabular}

$N_{i}$ is the weight percentages wt $\%$ of the $i$ th component composing the glass and $C_{i}$ or $C_{\mathrm{TE} i}$ is the coefficient associated with the $i$ th glass component. The terms $\left(C_{i} \cdot N_{i}\right)$ or $\left(C_{\mathrm{TE} i} \cdot N_{i}\right)$ can also include nonlinear combination of more than one glass component. Finally, $n$ represents the total number of terms.

The final step is to explicitly express the compositionviscosity or thermal expansion model that is specific to the bioactive glass composition set under study. In this study, the effort to present such a model is enlightened by the discussion of Kuppinger and Shelby [13], that is, inspecting possible interaction between ions composing the glass which may lead to the nonlinear relations of the bioactive glass composition with $E \mu$ and CTE. In this study, phosphorousalkali and alkaline earth effect is found. So, the suggested composition-glass property model is stated as below:

$$
\begin{aligned}
E \mu= & C_{1} \cdot \mathrm{wt} \% \mathrm{SiO}_{2}+C_{2} \cdot \mathrm{wt} \% \mathrm{P}_{2} \mathrm{O}_{5}+C_{3} \cdot \mathrm{wt} \% \mathrm{~K}_{2} \mathrm{O} \\
& +C_{4} \cdot \mathrm{wt} \% \mathrm{MgO}+C_{5} \cdot R_{11}+C_{6} \cdot R_{12}+C_{7} \cdot R_{21} \\
& +C_{8} \cdot R_{22}
\end{aligned}
$$

$$
\begin{aligned}
\mathrm{CTE}= & C_{\mathrm{TE} 1} \cdot \mathrm{wt} \% \mathrm{SiO}_{2}+C_{\mathrm{TE} 2} \cdot \mathrm{wt} \% \mathrm{P}_{2} \mathrm{O}_{5} \\
& +C_{\mathrm{TE} 3} \cdot \mathrm{wt} \% \mathrm{~K}_{2} \mathrm{O}+C_{\mathrm{TE} 4} \cdot \mathrm{wt} \% \mathrm{MgO} \\
& +C_{\mathrm{TE} 5} \cdot R_{11}+C_{\mathrm{TE} 6} \cdot R_{12}+C_{\mathrm{TE} 7} \cdot R_{21} \\
& +C_{\mathrm{TE} 8} \cdot R_{22} .
\end{aligned}
$$

$R_{11}, R_{12}, R_{21}$, and $R_{22}$ are first- and second-order functions of phosphorous-alkali and phosphorous-alkaline earth content:

$$
\begin{gathered}
R_{11}=\frac{\mathrm{wt} \% \mathrm{Na}_{2} \mathrm{O}}{\mathrm{wt} \% \mathrm{P}_{2} \mathrm{O}_{5}+\mathrm{wt} \% \mathrm{Na}_{2} \mathrm{O}} \\
R_{21}=\frac{\mathrm{wt} \% \mathrm{CaO}}{\mathrm{wt} \% \mathrm{P}_{2} \mathrm{O}_{5}+\mathrm{wt} \% \mathrm{CaO}} \\
R_{12}=\left(R_{11}\right)^{2} \\
R_{22}=\left(R_{21}\right)^{2} .
\end{gathered}
$$

Equations (4a)-(6b) are the model equations presented in this study that calculate $E \mu$ and CTE as function of the glass compositions.

\section{Modeling Technique}

Table 1 shows published bioactive glass composition data with their thermal properties [5]. In this table, Ts represent the temperature at constant viscosity level of $\mu=10^{6.6} \mathrm{~Pa} \cdot \mathrm{s}$, which corresponds to the Littleton softening temperature. $\mathrm{Tg}$ represents another constant viscosity level of $\mu=10^{12} \mathrm{~Pa} \cdot \mathrm{s}$, which is in the range of the expected glass transition temperature $\left(\mu=10^{11} \cdots 10^{12.3} \mathrm{~Pa} \cdot \mathrm{s}\right)$.

Utilizing (2), the two unknowns $(E \mu[k J]$ and $\ln A)$ can be found by substitution of Ts and Tg in Table 1. Figure 1 is a plot of $E \mu$ against - $\ln A$ which shows linear relation connecting them. The figure also shows the equation of the least-squares line passing through the data points. The reference values of $E \mu[k J]$ and $\ln A$ found utilizing Table 1 is used together with the glass compositions in $L^{2}$-regression [14] calculations. Accordingly, calculated glass properties $(E \mu c$ and $\mathrm{CTE} c)$ are found as function of their composition.

The assumption of linear additive behavior is firstly examined. This assumption yields to large differences between reference experimental and calculated glass properties. These differences remain at large values even when several combinations of the $\mathrm{wt} \%$ of oxide constituents are taken into account. The differences between the reference experimental and calculated glass properties are reduced only when phosphorous-alkali and alkaline earth effect as shown in $(4 a)-(6 b)$ is taken into account. The calculations astonishingly show that the nonadditive relations are equally needed for modeling of both $E \mu$ and CTE. The final rootmean-square error for $E \mu$ and CTE calculations are 26.47 and 0.23 , respectively. These are only around $2 \%$ of the reference experimental value for $E \mu$ and CTE.

Table 2 shows the reference experimental $E \mu$, reference experimental $\ln A$, calculated $E \mu$ via $L^{2}$-regression, calculated $\ln A$ (utilizing calculated $E \mu$ and the least-squares relation shown in Figure 1), reference experimental CTE, and calculated CTE via $L^{2}$-regression. The final coefficients $C_{i}$ and $C_{\mathrm{TE} i}$ that obtained by $L^{2}$-regression to calculate $E \mu$ and CTE for bioactive glasses are shown in Table 3 .

To find the temperature at a given viscosity value (an inverse problem), it needs to calculate $E \mu$ and $\ln A$ by the above methodology, then (2) can be solved for $T$. This can be accomplished using any numerical technique such as the "finite step method." Finally, setting $\mu$ to $20 \mathrm{~Pa} \cdot \mathrm{sec}$; the fusion temperature for a bioactive glass can be calculated [15].

To conclude, Figure 2 is a way to show how $E \mu$ and CTE respond to $\mathrm{CaO}$ and $\mathrm{Na}_{2} \mathrm{O}$ content. $E \mu$ and CTE are calculated by setting $\mathrm{K}_{2} \mathrm{O}, \mathrm{MgO}$, and $\mathrm{Na}_{2} \mathrm{O}$ to 3,6 , and $9 \mathrm{wt} \%$, respectively, and let $\mathrm{SiO}_{2}$ varies with $\mathrm{CaO}$ to make total contents to $100 \mathrm{wt} \%$. The same is done when varying 


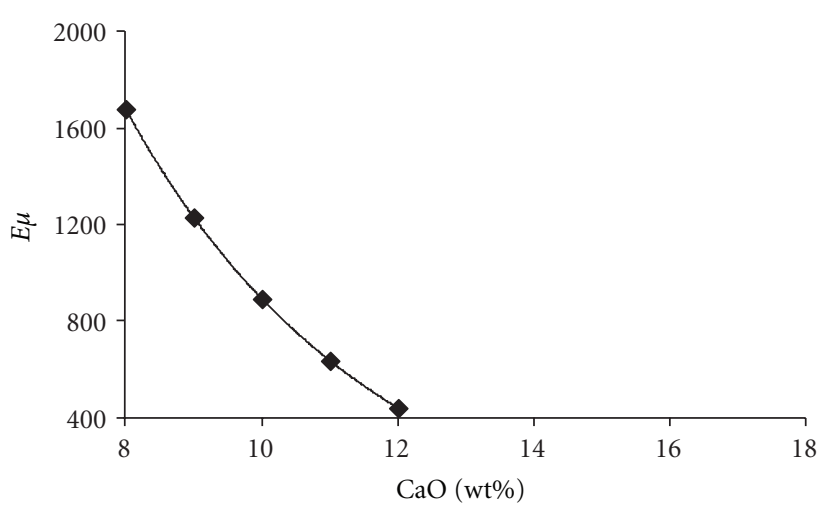

(a)

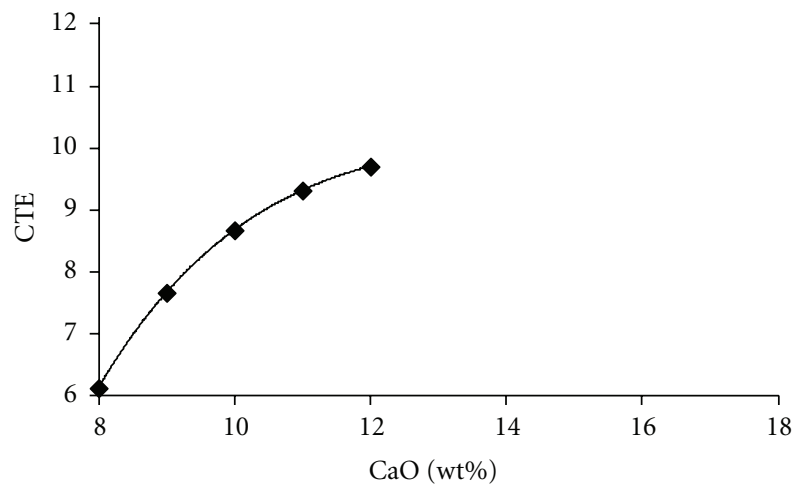

(c)

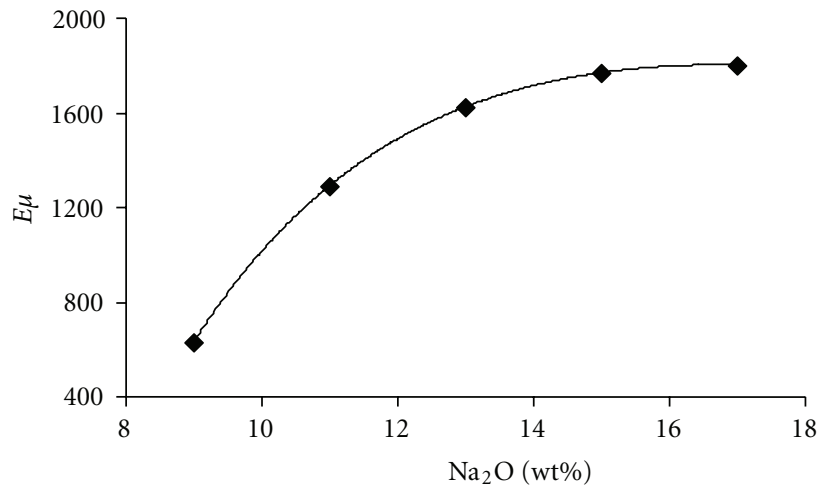

(b)

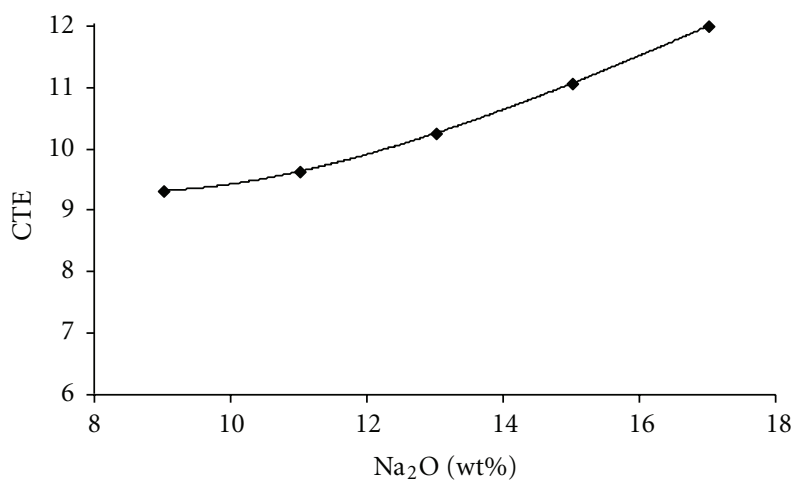

(d)

Figure 2: The variation of $E \mu$ and $\mathrm{CTE}$ with $\mathrm{CaO}$ and $\mathrm{Na}_{2} \mathrm{O}$ contents. Parts (a) and (b) show the variation of $E \mu$ with $\mathrm{CaO}$ and $\mathrm{Na}_{2} \mathrm{O}$ content. Parts (c) and (d) show the variation of CTE with $\mathrm{CaO}$ and $\mathrm{Na}_{2} \mathrm{O}$ contents.

$\mathrm{Na}_{2} \mathrm{O}$ by setting $\mathrm{K}_{2} \mathrm{O}, \mathrm{MgO}$, and $\mathrm{CaO}$ to 3,6 , and $11 \mathrm{wt} \%$, respectively. The figure is presented to show an example of the nonlinear behavior of $E \mu$ and CTE with $\mathrm{CaO}$ and $\mathrm{Na}_{2} \mathrm{O}$. Yet, $E \mu$ and CTE are linear with other oxide contents as shown in (4a)-(6b)

\section{Discussion}

Table 3 shows that $\mathrm{SiO}_{2}$ has a trend to increase $E \mu$ and to decrease CTE. At the same time, $\mathrm{P}_{2} \mathrm{O}_{5}$ tends to decrease both $E \mu$ and CTE. $\mathrm{MgO}$ shows similar behavior with $\mathrm{SiO}_{2}$; also, $\mathrm{K}_{2} \mathrm{O}$ behaves similar to $\mathrm{P}_{2} \mathrm{O}_{5}$ with different values of their coefficients. Figure 2 describes the behavior of $\mathrm{CaO}$ and $\mathrm{Na}_{2} \mathrm{O}$ more obviously. $\mathrm{Na}_{2} \mathrm{O}$ shows a trend to increase both $E \mu$ and CTE in nonlinear manner. The effect of $\mathrm{Na}_{2} \mathrm{O}$ is distinguished from that of $\mathrm{K}_{2} \mathrm{O}$ although they are both alkali oxides. Similarly, Figure 2 shows that $\mathrm{CaO}$ is decreasing $E \mu$ and increasing CTE in nonlinear fashion. This effect of $\mathrm{CaO}$ is also distinguished from that of $\mathrm{MgO}$ although they are both alkaline earth oxides.

The aforementioned different type of contribution for both $\mathrm{Na}_{2} \mathrm{O}$ and $\mathrm{CaO}$ to the viscosity and thermal expansion compared with that of $\mathrm{K}_{2} \mathrm{O}$ and $\mathrm{MgO}$, respectively, may be understood in view of that $\mathrm{Na} 2 \mathrm{O}$ and $\mathrm{CaO}$ content is generally higher than that of $\mathrm{K}_{2} \mathrm{O}$ and $\mathrm{MgO}$ in the bioactive glass as seen in Table 1. Consequently, large ion concentration of $\mathrm{Na}$ and $\mathrm{Ca}$ give a chance for $\mathrm{P}-\mathrm{Na}$ and $\mathrm{P}-\mathrm{Ca}$ interactions. These interactions are seen in a way that $\mathrm{P}_{2} \mathrm{O}_{5}$ is modifying the role of $\mathrm{Na}_{2} \mathrm{O}$ and $\mathrm{CaO}$ to that observed in Figure 2 and reflected formally in (9)(12). Nevertheless, those interactions on a relatively lowconcentration level of $\mathrm{K}_{2} \mathrm{O}$ and $\mathrm{MgO}$ do not influence the properties apparently. This explanation is illuminated by the discussion of Kuppinger and Shelby [13] that suggest short range ion-ion interaction in the glass medium that yields nonlinear relations of glass viscosity and thermal expansion with the oxide content. They study sodium potassium borate glasses with high sodium and potassium oxides contents which led to ion-ion interaction between the alkali ions. Nevertheless, in this study the high sodium and calcium oxide contents do not led to mutual interaction between them, but phosphorous-alkali and alkaline earth interaction takes place. The acidic nature of $\mathrm{P}_{2} \mathrm{O}_{5}$ may explain the interaction with alkali and alkaline earth oxides of the basic nature.

It is worth to mention that multilayer coating is one of the experimental experiences to avoid crack generation which originates from CTE mismatch [7]. However, multilayer coating may lead to other problems such as thick coating. As a direct application of the modeling presented in this study, a bioactive glass can be designed with suitable fusion temperature and CTE passing up lengthy experiments and cost. 


\section{Conclusions}

(1) Model relations of viscosity and thermal expansion with bioactive glass compositions have been obtained. The model allows the predictions of viscosity and thermal expansion for bioactive glass necessary in the field of glass science and technology.

(2) The model relations are discussed for the nonlinear behavior of viscosity and thermal expansion (deviation from additivity) with $\mathrm{Na}_{2} \mathrm{O}$ and $\mathrm{CaO}$ content. It is suggested that the deviation from additivity originates from short-range interaction between alkali and alkaline earth ions with phosphorus as formally presented in the model.

\section{References}

[1] O. V. Mazurin, "History, perspectives, and problems of measurement and calculation of glass properties," in Proceedings of the 3rd Balkan Conference on Glass Science and Technology, pp. 1-8, Varna, Bulgaria, 2005.

[2] O. V. Mazurin, "Glass properties: compilation, evaluation, and prediction," Journal of Non-Crystalline Solids, vol. 351, no. 1213, pp. 1103-1112, 2005.

[3] L. L. Hench, "The story of bioglass," Journal of Materials Science, vol. 17, no. 11, pp. 967-978, 2006.

[4] E. Saiz, M. Goldman, J. M. Gomez-Vega, A. P. Tomsia, G. W. Marshall, and S. J. Marshall, "In vitro behavior of silicate glass coatings on Ti6Al4V," Biomaterials, vol. 23, no. 17, pp. 37493756, 2002.

[5] J. M. Gomez-Vega, E. Saiz, A. P. Tomsia et al., "Novel bioactive functionally graded coatings on Ti6Al4V," Advanced Materials, vol. 12, no. 12, pp. 894-898, 2000.

[6] E. Vedel, H. Arstila, H. Ylänen, L. Hupa, and M. Hupa, "Predicting physical and chemical properties of bioactive glasses from chemical composition - part 1: viscosity characteristics," Glass Technology Part A, vol. 49, no. 6, pp. 251-259, 2008.

[7] E. Vedel, D. Zhang, H. Arstila, L. Hupa, and M. Hupa, "Predicting physical and chemical properties of bioactive glasses from chemical composition-part 4: tailoring compositions with desired properties," Glass Technology Part A, vol. 50, no. 1, pp. 9-16, 2009.

[8] K. Yang, W. H. Zheng, and J. S. Cheng, "Effect of $\mathrm{Li}_{2} \mathrm{O}$ on viscosity and thermal expansion of silicate glass," Advanced Materials Research, vol. 403-408, p. 7074, 2011.

[9] M. Wang, J. Cheng, M. Li, F. He, and W. Deng, "Viscosity and thermal expansion of soda-lime-silica glass doped with $\mathrm{Gd}_{2} \mathrm{O}_{3}$ and $\mathrm{Y}_{2} \mathrm{O}_{3}$," Solid State Sciences, vol. 14, no. 8, pp. 1233-1237, 2012.

[10] D. Bellucci, V. Cannillo, and A. Sola, "Coefficient of thermal expansion of bioactive glasses: available literature data and analytical equation estimates," Ceramics International, vol. 37, no. 8, pp. 2963-2972, 2011.

[11] G. Urbain, F. Cambier, M. Deletter, and M. R. Anseau, "Viscosity of silicate melts," Transactions \& Journal of the British Ceramic Society, vol. 80, pp. 139-141, 1981.

[12] I. N'dala, F. Cambier, M. R. Anseau, and G. Urbain, "Viscosity of liquid feldspars_-part I: viscosity measurements," Journal of the British Ceramic Society, vol. 83, no. 4, pp. 105-107, 1984.

[13] C. M. Kuppinger and J. E. Shelby, "Viscosity and thermal expansion of mixed alkali sodium potassium borate glasses,"
Journal of the American Ceramic Society, vol. 68, no. 9, pp. 463467, 1985.

[14] R. J. Vanderbei, Linear Programming: Foundations and Extensions, Princeton University, Princeton, NJ, USA, 2001.

[15] J. R. Taylor and A. C. Bull, Ceramics Glaze Technology, Pergamon Press, New York, NY, USA, 1986. 

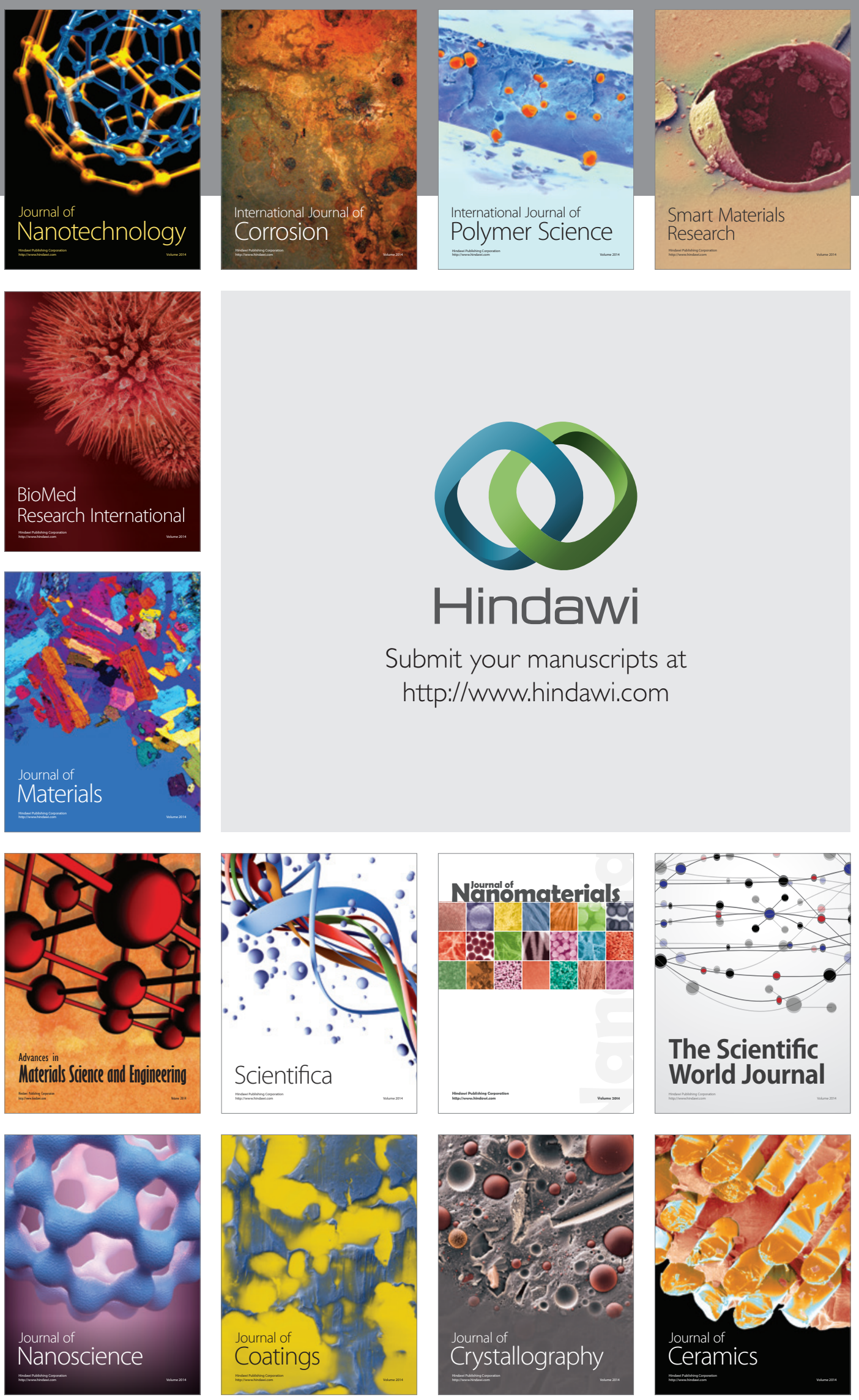

The Scientific World Journal

Submit your manuscripts at

http://www.hindawi.com

\section{World Journal}

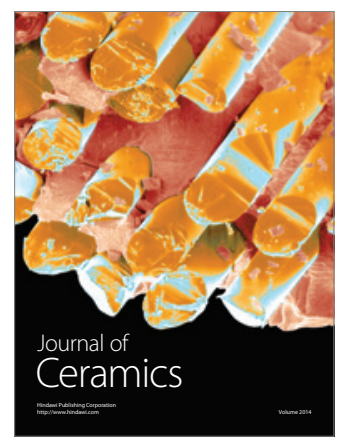

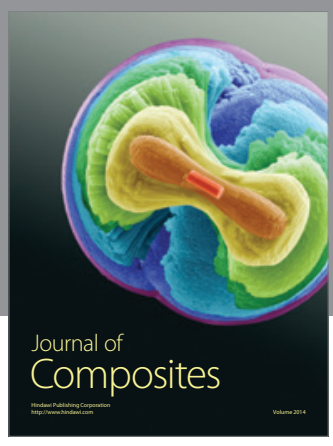
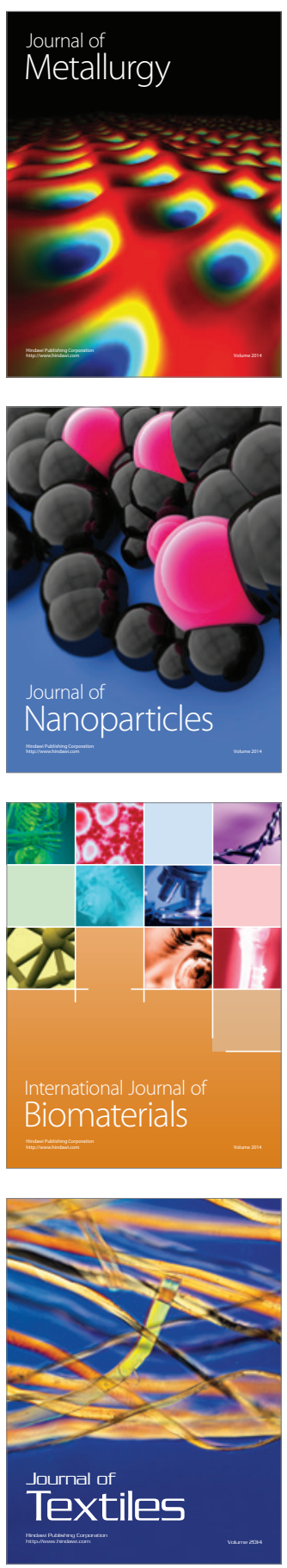